\title{
Optimization of a MALDI TOF-TOF Mass Spectrometer for Intact Protein Analysis
}

\author{
Zhaoyang Liu and Kevin L. Schey \\ Department of Cell and Molecular Pharmacology, Medical University of South Carolina, Charleston, \\ South Carolina, USA
}

\begin{abstract}
A MALDI TOF-TOF instrument was optimized and evaluated for intact protein analysis by tandem mass spectrometry. Ion source voltages and delay times were adjusted to affect an up to a 10-fold improvement in fragment ion yield compared to data obtained using default settings employed in peptide analysis. For large peptides ( $3-4.5 \mathrm{kDa}$ ), up to $90 \%$ of all possible $\mathrm{b}$ - and $\mathrm{y}$-fragment ions were observed, which provides sufficient information for de novo sequencing and unambiguous protein identification. Product ion signals associated with preferential cleavages $\mathrm{C}$-terminal to aspartic acid and glutamic acid residues and $\mathrm{N}$-terminal to proline residues became dominant with increased protein molecular weight. Matrix effects were also evaluated and, among the eight matrices examined, $\alpha$-cyano-4-hydroxycinnamic acid (CHCA) was found to produce the best intact protein tandem mass spectra for proteins up to $12 \mathrm{kDa}$. Optimized performance yielded detection limits of 50-125 fmol for proteins of 4 and $12 \mathrm{kDa}$, respectively. This improved performance has yielded an instrument with potential to be a useful tool in proteomic investigations via analysis of intact proteins. (J Am Soc Mass Spectrom 2005, 16, 482-490) @ 2005 American Society for Mass Spectrometry
\end{abstract}

S ince the introduction of matrix-assisted laser desorption/ionization (MALDI) [1-3] and electrospray ionization (ESI) [4], mass spectrometry has become the primary tool for the analysis of protein primary structure. Coupling of 2-D gel electrophoresis or chromatographic separation approaches with mass spectrometry has become the standard approach for proteome analysis [5, 6]; however, technological improvements continue to be made to improve performance in the demanding analysis of proteomes. The introduction of MALDI TOF-TOF technology [7] represents one such advancement offering the advantages of MALDI ionization with tandem mass spectrometry in a time-of-flight instrument. The high throughput and sensitivity features of the instrument make it an attractive platform for proteomics research. Furthermore, the theoretical unlimited mass range of time-of-flight and the high collision energy employed in the TOF-TOF instrument are capabilities that make the exploration of tandem mass spectrometric analysis of larger peptides and intact proteins possible. This strategy, termed the "top-down" approach, has been successfully implemented in Fourier transform mass spectrometers [8] and quadrupole ion traps [9].

An attractive feature of the "top-down" approach is that no enzymatic digestion is required, so that the analysis time is dramatically shortened and sensitivity

Published online February 10, 2005

Address reprint requests to Professor K. L. Schey, Department of Cell and Molecular Pharmacology, Medical University of South Carolina, 173 Ashley Ave., P.O. Box 250505, Charleston, SC 29425, USA. E-mail: scheykl@ musc.edu potentially enhanced. The key objective in "top-down" analysis is to efficiently fragment intact proteins to obtain sequence-specific information for database searching and protein identification. To date, the most successful technique for "top-down" analysis is the coupling of electron capture dissociation (ECD) and ESI with high resolution FTICR mass spectrometry [10, 11], where proteins with masses up to 42,000 Da have been sequenced [12]. In early studies, the upper mass limit for fragmentation by CID has been reported to be approximately $2500 \mathrm{Da}$ for singly charged precursor ions [13, 14]; however, multiply charged proteins as large as $150 \mathrm{k}$ Da have been dissociated by CID [15].

ECD and CID efficiencies depend on the internal energy deposition after ionization and precursor ion selection. Until recently, fragmentation observed in MALDI experiments has relied on internal energy acquired during ionization as observed by ion-source decay (ISD) and post-source decay (PSD); the two differing by the time-frame for fragmentation. ISD occurs within several hundred nanoseconds after laser firing while PSD occurs in the microsecond range. The most abundant fragment ions observed in ISD of a variety of proteins are c- and y-ions [16-19]. ISD of peptides has been examined to determine the influence of the matrix, the susceptibility of amino-acid residues to ISD, and the effect of extraction delay times [20]. The most suitable matrix for ISD was 2,5-dihydroxybenzoic acid (DHB). The influence of the nature of the constituent amino acids on positively charged product ions was also investigated, including strong dependence on the location(s) of basic arginine and lysine residues [19, 
21]. Proteins as large as thioredoxin, $12 \mathrm{kDa}$, have been observed to fragment by PSD [22] where sequencespecific cleavage $\mathrm{N}$-terminal to proline residues was observed.

Recently, a MALDI TOF mass spectrometer with the novel "LIFT" technique (MALDI LIFT-TOF/TOF MS) was developed [23] featuring the ability to analyze fragment ions generated by any one of three different modes of dissociation: laser-induced dissociation (LID), high-energy CID, and ISD. N-terminal and C-terminal fragment ion series, providing near terminal sequence tags from undigested protein, were obtained by ISD. The ISD fragments were selected in the timed ion gate of a MALDI-TOF/TOF mass spectrometer for MS/MS analysis [24].

The emergence of a new MALDI TOF-TOF mass spectrometer, the Applied Biosystems 4700 proteomics analyzer (Foster City, CA), makes it possible to obtain sequence specific information from intact protein without proteolytic treatment. The initial report of the instrumental capabilities successfully demonstrated this approach for proteins up to molecular weight of 12 $\mathrm{kDa}$ [25]. As was observed previously by CID [26], product ions resulting from preferential cleavage at aspartyl and prolyl residues dominate the tandem mass spectrum. Nonpreferential cleavage, which provides additional information in protein identification, was also observed. Given the fact that the ion optics of the Applied Biosystems 4700 instrument were designed for tandem mass spectrometry analysis of tryptic peptides, we attempted to optimize the instrumental parameters for the analysis of large peptides and intact proteins. Here we report the results of this optimization as well as the matrix effects on MS/MS spectra from MALDI TOF-TOF experiments.

\section{Experiment}

\section{Materials}

Recrystallized $\alpha$-cyano-4-hydroxycinnamic acid (CHCA) was purchased from Bruker (Billerica, MA). All other matrices, 3-indoleacetic acid (IAA), 2-mecaptobenzothiazole $(\mathrm{MBT})$, umbelliferone (UBF), tetrahydroxyquinone (THBP), sinapinic acid (SA), ferulic acid (FA), and 2-(4hydroxyphenylazo)benzoic acid (HABA), as well as peptides/proteins were obtained from Sigma (St. Louis, MO), and used without any further treatment. Matrix solutions were prepared at a concentration of $10 \mathrm{mg} / \mathrm{ml}$ in 50:50 acetonitrile/water $(0.1 \%$ TFA). For matrices with solubility less than $10 \mathrm{mg} / \mathrm{ml}$, saturated solutions were employed. Except where specified, the concentration of all peptide/protein solutions is $10 \mathrm{pmol} / \mu \mathrm{l}$. Aliquots of $1 \mu \mathrm{l}$ of a 1:1 mixture of matrix and peptide/protein solutions were spotted on a sample plate and allowed to air dry prior to insertion into the mass spectrometer; therefore, the amount of sample spotted is $5 \mathrm{pmol} / \mu \mathrm{l}$.

\section{Mass Spectrometry}

All experiments were carried out on an Applied Biosystems 4700 proteomics analyzer equipped with TOF/ TOF ion optics and a diode pumped Nd:YAG laser with $200 \mathrm{~Hz}$ repetition rate. The operating principle of this mass spectrometer was detailed previously [27]. The MS/MS capabilities of the instrument are facilitated through a timed ion selector (TIS), a deceleration lens, a collision cell, and a second ion source. After deceleration by the deceleration lens, the mass-selected precursor ions collide with collision gas in a field-free collision cell. The potential difference between acceleration voltage and floating collision cell defines the collision energy, which is $1 \mathrm{keV}$ in all experiments. All fragments formed from precursor ions in the collision cell travel with essentially the same velocity as the precursor ion, and thus, enter the second source at the same time as the precursor ion. When the collection of precursor and fragment ions has entered the second source, a high voltage pulse is applied to the source and the ions are accelerated towards the detector. When the instrument is operated in MS/MS mode, the first source is operated as a two stage, delayed extraction, linear TOF MS with an $8 \mathrm{kV}$ acceleration voltage. For a given precursor ion mass, instrument geometry and operation voltages, the extraction delay times in both ion sources, and the arrival time of the precursor ion to the TIS are calculated by the instrument control program.

All the MS/MS spectra resulted from accumulation of at least 4000 laser shots. Air was used as the collision gas such that nominally single collision conditions were achieved. Since there is only one component in the sample, a wide mass window was utilized so that all the precursor ions could pass the gate to enter the collision. Generally, the width of mass window is set to $50 \mathrm{Da}$ if the mass of precursor ion is less than $5000 \mathrm{Da}, 100 \mathrm{Da}$ for precursor masses between $5000 \mathrm{Da}$ and $9000 \mathrm{Da}$, and $200 \mathrm{Da}$ for masses between $9000 \mathrm{Da}$ and 12,000 Da. MS/MS data were acquired using the instrument default calibration, without applying internal or external calibration.

\section{Results and Discussion}

\section{Tuning of the Instrument}

The influence of voltages on einzel lens and grid. Optimization of the instrument tuning parameters was attempted in an effort to improve MS/MS performance for intact proteins with molecular weights up to $12 \mathrm{kDa}$. A schematic is presented in Figure 1 to indicate ion optical elements of the instrument. The voltages applied to source $1(8 \mathrm{kV})$, source $2(15 \mathrm{kV})$, ion mirror $1(10.23$ $\mathrm{kV})$, ion mirror $2(15.885 \mathrm{kV})$, and collision cell $(7 \mathrm{kV})$ were kept at their default values. The deflector voltages $(\mathrm{X} 1, \mathrm{Y} 1, \mathrm{X} 2, \mathrm{Y} 2$ and $\mathrm{X} 3, \mathrm{Y} 3)$ were optimized according to the manufacturer's protocol. The function of einzel lens 1 , as well as the deceleration stack, is to focus the ion 


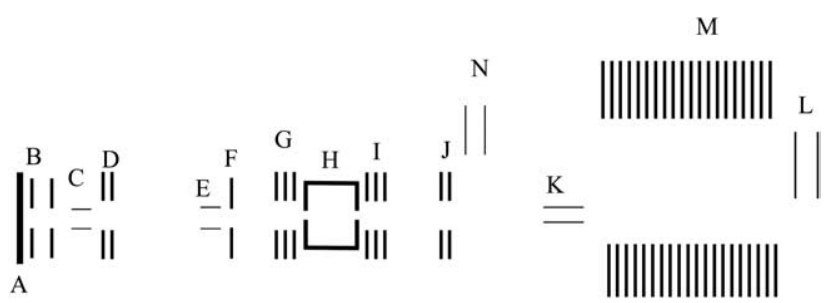

Figure 1. Schematics of MALDI TOF-TOF mass spectrometer. (a) Sample plate; (b) grid 1; (c) X1/Y1 deflectors; (d) einzel lens 1; (e) $\mathrm{X} 2 / \mathrm{Y} 2$ deflectors; (f) timed-ion selector; (g) retarding lens; (h) collision cell; (i) second ion source; (j) einzel lens 2; (k) X3/Y3 deflectors; 1) linear detector; (m) 2-stage ion mirror; (n) reflector detector.

beam so as to maximize transmission of precursor ions to the collision cell. The voltages applied to einzel lens 1 and grid 1 were found to dramatically influence product ion intensity. In contrast, variation of the voltages applied to einzel lens 2 does not have a significant effect on product ion signal. The delayed extraction time for ion source 1 (DE1) is an additional parameter that affects MS/MS sensitivity, especially for proteins with higher molecular weight. Hereafter, we refer to the optimized settings as modified settings and manufacturer's settings as standard settings. Table 1 lists all the parameter values before and after optimization. A comparative experiment was conducted using ubiquitin (MW 8564.72 Da) and thioredoxin (MW 11674.4 Da) as samples. Three replicates were spotted for each sample. Operating in batch mode, MS/MS spectra were initially acquired employing standard settings, followed by acquisition using modified settings. Five thousand laser shots were accumulated for each sample spot. Overall, a 6-fold increase in product ion intensity was achieved with the modified settings.

The MS/MS spectra of ubiquitin from bovine erythrocytes (MW 8564.72 Da) in Figure 2 demonstrate the increase of fragment ion signals after optimization. The intensities of product ions obtained under modified settings are almost four times greater than those acquired with standard settings. Due to higher sensitivity, more product ions were observed in the low mass region $(m / z<2000 \mathrm{Da})$, such as $\mathrm{y} 9, \mathrm{y} 10, \mathrm{y} 11-\mathrm{NH}_{3}, \mathrm{y} 12$, $\mathrm{y} 13, \mathrm{y} 13, \mathrm{y} 15, \mathrm{y} 16$, and $\mathrm{y} 17-\mathrm{NH}_{3}$, and the peaks between $\mathrm{y} 18$ and $\mathrm{y} 24$, such as $\mathrm{y} 19-\mathrm{NH}_{3}$ and $\mathrm{y} 22-\mathrm{NH}_{3}$. The observation of those peaks provides sufficient information to obtain the sequence tag and furthermore to identify the protein. Note that the broad peak centered at $5452 \mathrm{Da}$ is caused by electronic noise from the metastable suppression.

Table 1. Parameter values before and after optimization

\begin{tabular}{lcc}
\hline Parameters & Standard $(\mathrm{kV})$ & Modified $(\mathrm{kV})$ \\
\hline \hline Grid 1 & 6.85 & 7.05 \\
Lens 1 & 4.10 & 3.95 \\
Deceleration Stack & 4.1 & 3.9 \\
\hline
\end{tabular}
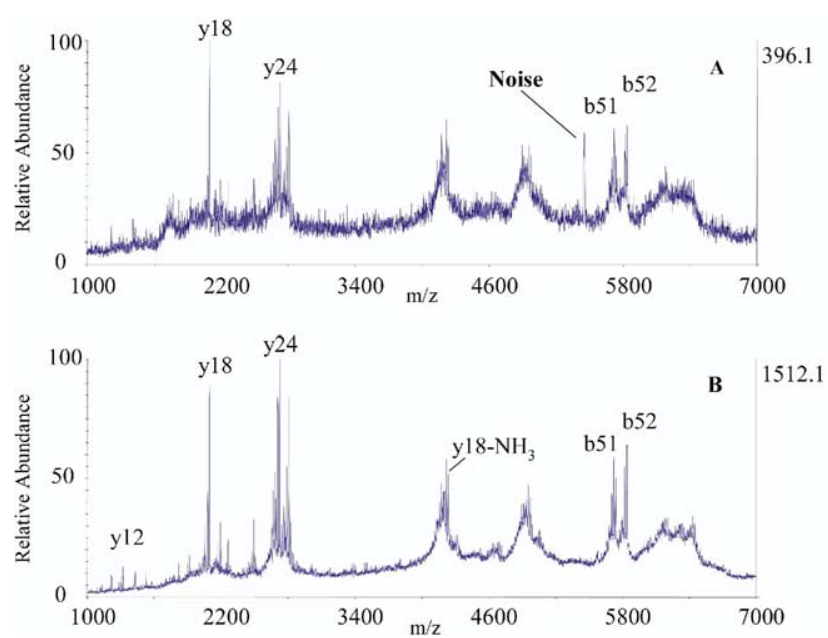

Figure 2. MALDI TOF-TOF spectra of ubiquitin $(\mathrm{m} / z$ 8564.7 Da selected) obtained using standard settings (a) and modified settings (b). All other experimental parameters are the same. Five pmol of ubiquitin was spotted.

The influence of delay time. Delayed extraction is widely employed in TOF mass spectrometry to improve mass resolution [28]. The abundance of protonated analyte ions generated by MALDI can be maximized at an optimum delay time of a few hundred nanoseconds, varying with the geometry of instrument. The ion abundance at the optimum delay time exceeds that of prompt extraction by a factor of two or more [29]. Since the dissociation rate is fixed for a given set of experimental conditions (collision energy, matrix and laser irradiance), more precursor ions extracted from the ion source will yield more product ions. Figure shows the MS/MS mass spectra of thioredoxin (MW 11674.4 Da) with delay times of $650 \mathrm{~ns}$ and $2530 \mathrm{~ns}$, the latter being the default delay time calculated by the instrument control software. The product ion abundance increased gradually with decreasing delay time from $2530 \mathrm{~ns}$ to 650 ns. Further decreasing delay time leads to weaker product ion signals. The product ion intensities of thioredoxin obtained at optimum delay time (650 ns) are more than five times greater than those obtained at $2530 \mathrm{~ns}$. One possible explanation for this observation is that shorter delay times select for "hotter" ions thereby improving observed product ion intensities. With the enhanced sensitivity, more product ions were observed, both at the lower mass region and high mass region. In the low mass region of Figure 3a, there are many product ions, corresponding to non-preferential cleavages of amide bonds, which are not observed in Figure $3 \mathrm{~b}$. The y93 and y95 peaks in high mass region of Figure $3 b$ are barely distinguishable from the noise and the y98 and y99 ions are totally absent. It is notable that for proteins with lower molecular weight, the change of delay time did not have such a dramatic effect on product ion yields. For all proteins less than $12,000 \mathrm{Da}$, the optimum delay time falls in the range of 400 to $700 \mathrm{~ns}$, which is in good agreement with previous investigation [29]. 

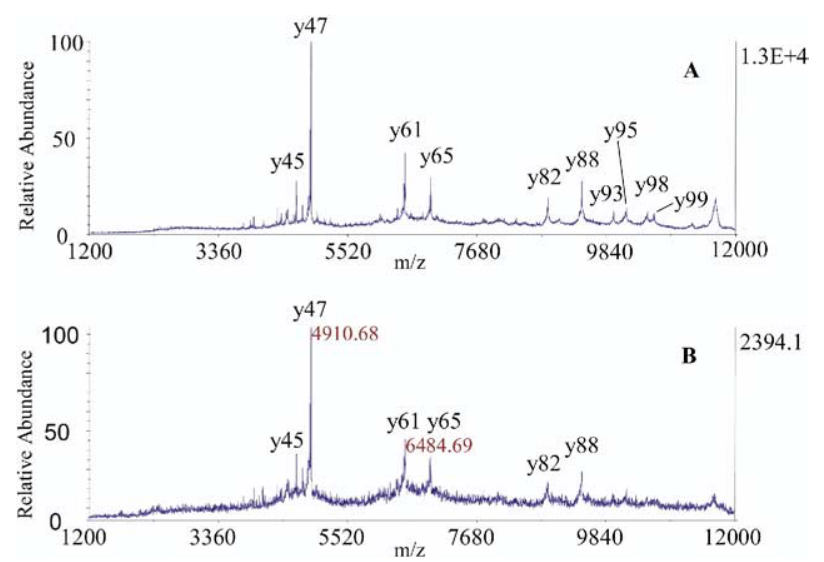

Figure 3. MALDI TOF-TOF spectra of thioredoxin $(\mathrm{m} / \mathrm{z} 11674 \mathrm{Da}$ selected) obtained with delay time of ion source 1 at (a) $650 \mathrm{~ns}$ and (b) $2530 \mathrm{~ns}$. The default delay time $(2530 \mathrm{~ns})$, based on the molecular weight of precursor and other parameters, is calculated by the instrument control software. All other experimental parameters are identical for both spectra. Approximately 22 pmol of thioredoxin was spotted.

\section{Matrix Effects on MALDI MS/MS}

It is well known that matrix plays an important role in the ion yield and fragmentation efficiency in desorption/ionization of proteins from crystalline matrices. Thus, the choice of matrix has a large effect on the recorded mass spectrum. During the desorption/ionization process, proteins not only acquire a proton from the matrix, but also receive internal energy through the proton transfer reaction. The amount of internal energy transferred to protein ions defines the "hot" or "cold" characteristics of matrix. Here, a variety of matrices, from "hot" to "cold", were selected to study the matrix effects on the fragmentation efficiency and fragmentation patterns of intact proteins. Among all the matrices used for UV-MALDI, CHCA is widely used for peptide mass mapping experiments. This matrix is known for its tendencies to induce post-source decay (PSD) [30] and higher charge state ions [31]. Sinapinic acid [32] and HABA [33] are particularly beneficial for ionization of higher molecular weight proteins. MBT was found to be able to produce ions of various analytes [34]. IAA was employed as matrix for the ionization of synthetic polymers [35]. In this study, THBP was selected because of its ability to produce abundant PSD signals [36], and UBF was chosen because of its (presumably) much different proton transfer process, suggested by its chemical structure. CHCA, MBT, and IAA were considered as "hot" matrices as determined by the simultaneous measurement of neutral and ion abundances [37]. In addition, the location of protonation sites could differ because of different proton transfer processes, thereby affecting the fragmentation pattern, according to the mobile proton mode proposed by Wysocki et al. [38].

MALDI TOF-TOF mass spectra of insulin obtained using various matrices are presented in Figure $4 a, b, c$, $\mathrm{d}, \mathrm{e}$, and $\mathrm{f}$. All the spectra were acquired at the same experimental conditions with the exception of laser irradiation, which was optimized for each matrix. Based on the sequence and structural information (detailed below) acquired using CHCA as the matrix, the tandem mass spectrum is composed of four segments: (1) the low mass region to $m / z 1500$ Da containing product ions of the insulin chain B, (2) the segment from $1800 \mathrm{Da}$ to $2600 \mathrm{Da}$ dominated by cleavage of the one of the inter-disulfide bonds with intact A-chain signal, (3) the region between $3200 \mathrm{Da}$ and $3500 \mathrm{Da}$ characterized by B-chain signals after asymmetric dissociation of disulfide bonds linking the A-chain and B-chain, and (4) the high mass region, $3700 \mathrm{Da}$ to $5500 \mathrm{Da}$, featuring cleavage of amino acid residues from the N-terminus of the A-chain. According to the "hot" or "cold" nature of matrix, not all segments are observed for each matrix, especially for the mass regions from $1800 \mathrm{Da}$ to $2600 \mathrm{Da}$ and $3700 \mathrm{Da}$ to $5500 \mathrm{Da}$. For example, it is hard to obtain any useful information when SA was used as matrix, as shown in Figure 4d. There are no ion signals in regions from $1800 \mathrm{Da}$ to $2600 \mathrm{Da}$ and $3700 \mathrm{Da}$ to $5500 \mathrm{Da}$, using IAA and UBF as matrix. Except for the product ion using CHCA as matrix, the relative intensities of product ion are almost the same, indicating different proton distributions among the protein ions when ionized by CHCA.

The quintet centered at $\mathrm{m} / \mathrm{z} 3396.49$, formed by asymmetric cleavage of both disulfide bonds connecting the A-chain and B-chain [39] dominates the tandem mass spectra, regardless the matrix employed. The relative intensity of the quintet, compared with the precursor ion, reveals the internal energy transferred to insulin during the desorption/ionization process. The intensities of survived precursor ions are almost the same using CHCA, IAA, MBT, and UBF; however, the intensities of product ion differ dramatically. CHCA and HABA were found to most efficiently produce product ions; MBT ranking slightly lower in sequence information.

Figure $5 a, b, c$, and d show tandem mass spectra of
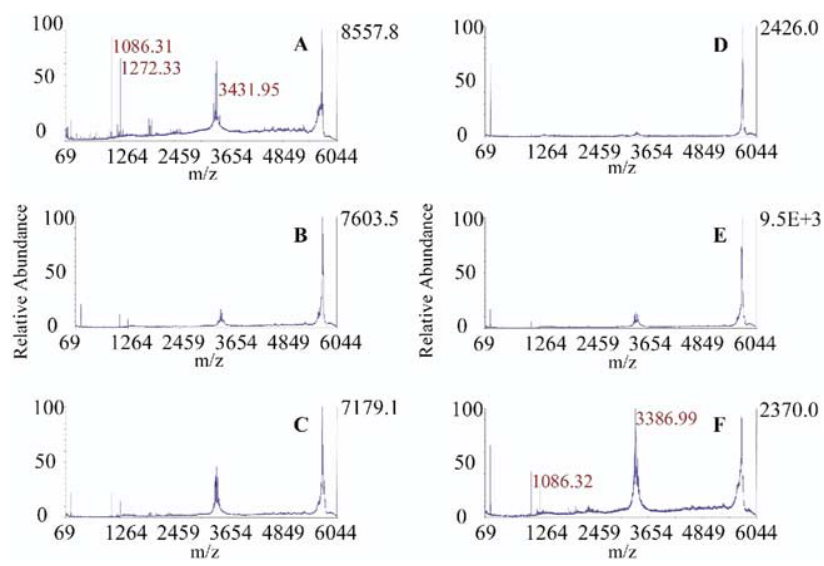

Figure 4. MALDI TOF-TOF spectra of insulin $(\mathrm{m} / z$ 5733.49 Da selected) obtained using various matrices. (a) CHCA, (b) IAA, (c) MBT, (d) SA, (e) THBP, and (f) HABA. 

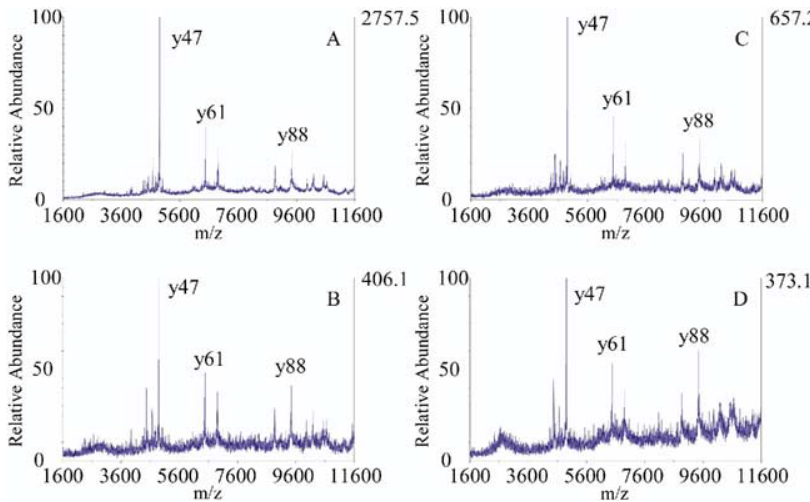

Figure 5. MALDI TOF-TOF spectra of thioredoxin $(\mathrm{m} / z 11674 \mathrm{Da}$ selected) obtained using different matrices. (a) CHCA, (b) MBT, (c) THBP, and (d) HABA.

thioredoxin acquired using CHCA, MBT, THBP and HABA as matrices, respectively. The signal intensities of product ions obtained using CHCA are much higher than other matrices, yielding more sequence information, particularly in the low-mass region $(\mathrm{m} / \mathrm{z}$ less than $4900 \mathrm{Da})$, where nonpreferential cleavages were found [25]. As for preferential cleavages in the higher mass region, although the ion signals are not as strong as those with CHCA, all the fragments detected using other matrices are essentially the same, e.g., y61, y65, y82, y88, y93, y95, y98, and y99. Fewer fragments and lower intensities were detected when other matrices, such as SA and IAA, were employed.

Although the product ions obtained using different matrices vary (both ion species and intensities), no new fragment types were observed. Previous investigations on in-source decay showed the observed ion series varied significantly depending on the matrix used [24, 40]. For example, c-ions dominate the ISD spectrum, regardless of the matrix, a- and y-ions increase if DHB is used, and the formation of a-ions is dramatically enhanced by CHCA. The significant difference of the matrix effect on ISD compared to PSD/CID is possibly caused by the different fragmentation mechanisms or energy transfer pathway. It has been proposed that the reaction of free electrons in the MALDI plume with analyte ions (possibly multiply-charged ions) leads the very fast decay of precursor ions [41]. This is consistent with the observed ISD ion series being similar to those of electron-capture dissociation.

\section{Complete Sequence Coverage}

The ability to perform de novo sequencing of small peptides using Applied Biosystems 4700 proteomic analyzer was presented by Yergey et al. [27], where only peptides with MW less than 2000 Da were sequenced de novo. With our optimized instrument settings and matrix choices described above, nearly complete sequence coverage of a 31 amino acid peptide, human $\beta$-endorphin (YGGFMTSEKSQT-
PLVTLFKNAIIKNAYKKGE) was observed. The MALDI TOF-TOF mass spectrum is shown in Figure 6 and Table 2 lists the calculated and observed $y$ - and $\mathrm{b}$-ions. The entire y-ion series is observed with the exception of the first (y1) and the last (y30). Although most of the b-ion intensities are weak, only the b13 and b30 ion are not detected. Due to isotopic overlap, the assignment of the $y 17$ ion $(m / z$ 1838.05) and the b17 ion $(\mathrm{m} / z$ 1840.92) is precluded. Overall, only four out of 59 total b- and y-product ions were not observed in Figure 6. The most abundant peak in the spectrum is the y19 ion, the intensity of which is more than twice that of the next highest peak, the y16 ion. The $y 19$ fragment ion corresponds to the cleavage of an Xxx-Pro amide bond. The preferential cleavage of Xxx-Pro amide bond was first observed by Loo et al on CID of multiply charged proteins produced by ESI [42]. In agreement with previous observation [26], the intensity of the adjacent y18 ion is weak. Furthermore, the signal for the complementary b12 ion (marked by an asterisk), is also relatively strong among the observed b-ions. There are no other preferential cleavages observed, even though there are two acidic amino acid residues, glutamic acid, at the position of 8 and 31. Another feature of the $\beta$-endorphin spectrum under our experimental conditions is the enhanced $b$-ion signals in the higher mass region. Below $m / z$ 2200, y-ions dominate; however, at higher mass region, the $b$-ion intensities are relatively strong. With over $93 \%$ of b- and y-ions observed, protein identification can be accomplished with confidence.

As higher molecular weight peptides are examined, more preferential cleavages are observed, as demonstrated in Figure 7 with human glucagon-like peptide I (HDEFERHAEGTFTSDVSSYLEGQAAKEFIAWLVKGRG, MW $4168.46 \mathrm{Da})$. The increase in preferential cleavage may be caused by the additional arginine risidue ( $2 \mathrm{Arg}$ in glucagon, compared only 1 in $\beta$-endophin) [38]. Similar to $\beta$-endorphin, more than $90 \%$ of the $b$ - and y-product ions are observed (as listed in

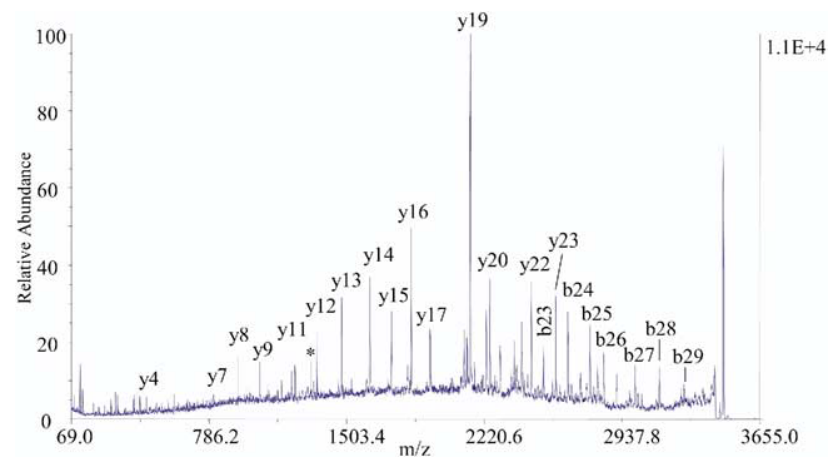

Figure 6. MALDI TOF-TOF spectrum of human $\beta$-endorphin $(\mathrm{m} / \mathrm{z} 3465.4$ selected) obtained under optimized experimental conditions. The $\mathrm{y}$ - and b-ions detected are listed in Table 2. The peak donated by an asterisk is the b12 ion, the complementary of the $y 19$ ion. 
Table 2. Theoretical and measured masses of MALDI TOF-TOF production ions of human \&303B2;-endorphin. Over 93 percent of $b$ - and $y$-ions are observed under optimized condition

\begin{tabular}{|c|c|c|c|c|c|}
\hline T1 & Theoretical & Measured & & Theoretical & Measured \\
\hline y1 & 148.06 & & & & \\
\hline y2 & 205.08 & 205.10 & b2 & 221.09 & 221.09 \\
\hline y3 & 333.18 & 333.16 & b3 & 278.11 & 278.13 \\
\hline y4 & 461.27 & 461.23 & b4 & 425.18 & 425.16 \\
\hline y5 & 624.34 & 624.27 & b5 & 556.22 & 556.21 \\
\hline y6 & 695.37 & 695.28 & b6 & 657.27 & 657.27 \\
\hline y7 & 809.42 & 809.33 & b7 & 744.3 & 744.29 \\
\hline y8 & 937.51 & 937.43 & b8 & 873.35 & 873.28 \\
\hline y9 & 1050.59 & 1050.52 & b9 & 1001.44 & 1001.43 \\
\hline y10 & 1163.68 & 1163.60 & b10 & 1088.47 & 1088.39 \\
\hline y11 & 1234.72 & 1234.63 & b11 & 1216.53 & 1216.45 \\
\hline y12 & 1348.76 & 1348.67 & b12 & 1317.58 & 1317.49 \\
\hline y13 & 1476.85 & 1476.77 & b13 & 1414.63 & \\
\hline y14 & 1623.92 & 1623.84 & b14 & 1527.72 & 1527.66 \\
\hline y15 & 1737.01 & 1736.94 & b15 & 1626.78 & 1626.76 \\
\hline y16 & 1838.05 & 1837.99 & b16 & 1727.83 & 1727.81 \\
\hline y17 & 1937.12 & 1937.06 & b17 & 1840.92 & \\
\hline y18 & 2050.21 & 2050.17 & b18 & 1987.98 & 1987.93 \\
\hline y19 & 2147.26 & 2147.23 & b19 & 2116.08 & 2116.08 \\
\hline y20 & 2248.31 & 2248.28 & b20 & 2230.12 & 2230.12 \\
\hline y21 & 2376.37 & 2376.34 & b21 & 2301.16 & 2301.14 \\
\hline y22 & 2463.4 & 2463.40 & b22 & 2414.24 & 2414.25 \\
\hline y23 & 2591.49 & 2591.52 & b23 & 2527.33 & 2527.33 \\
\hline y24 & 2720.54 & 2720.60 & b24 & 2655.42 & 2655.44 \\
\hline y25 & 2807.57 & 2807.62 & b25 & 2769.46 & 2769.52 \\
\hline y26 & 2908.61 & 2908.71 & b26 & 2840.5 & 2840.56 \\
\hline y27 & 3039.66 & 3039.66 & b27 & 3003.57 & 3003.62 \\
\hline y28 & 3186.72 & 3187.71 & b28 & 3131.66 & 3131.68 \\
\hline y29 & 3243.75 & 3243.59 & b29 & 3259.76 & 3259.73 \\
\hline y30 & 3300.77 & & b30 & 3316.78 & \\
\hline
\end{tabular}

Table 3). Note that some peaks cannot be unambiguously assigned due to isotopic overlap. Those peaks include b6 $(\mathrm{m} / \mathrm{z} 814.35)$ and y7 $(\mathrm{m} / \mathrm{z} 815.39)$, b16 $(\mathrm{m} / \mathrm{z}$ $1858.8)$ and $\mathrm{y} 17(\mathrm{~m} / \mathrm{z} 1860.01), \mathrm{b} 20(\mathrm{~m} / \mathrm{z} 2309.01)$ and y21 $(\mathrm{m} / \mathrm{z}$ 2310.22), and b30 (m/z 3353.54) and y31 $(\mathrm{m} / \mathrm{z}$ 3354.68). Preferential cleavages at aspartic acid and glutamic acid residues are observed giving rise to intense product ion signals. There are two aspartic acid residues (position 2, 15) and 5 glutamic acid residues (position 3, 5, 9, 21, 27), which result in the strong signals for $\mathrm{y} 10, \mathrm{y} 16, \mathrm{y} 22, \mathrm{y} 28, \mathrm{y} 32, \mathrm{y} 34$, and y35 ions, as marked by asterisks in Figure 7. Formation of complementary b-ions produced from the preferential cleavages described above is also detected, such as b9, b15 and b21. The peak intensities of the other complementary b-ions, namely b2, b3 and b5 are not outstanding. It has been previously reported [26] that fragmentation of peptides containing both arginine and aspartic acid/ glutamic acid yields intense $y$-ions if the Arg residue is located C-terminal to the acidic residues, or b-ions if the Arg residue is located N-terminal to the acidic residues. The weak peaks of $b 2, b 3$, and b5 and the intense peaks of b9, b15, and b21 confirm the conclusion of $Q$ in and Chait [26].

In addition to primary sequence determination, the identification of post-translational modification is also important, especially in regard to protein func- tion. Here, we demonstrate the direct determination of disulfide bonds in insulin using the TOF-TOF tandem mass spectrometer. Using standard settings, Lin et al. [25] only observed the quintet and partial fragments of the insulin B-chain. Figure 8a, b, c, and $\mathrm{d}$ show four segments of the mass spectrum of insulin separated according to fragmentation features, as well as mass region. In Figure 8a, two peaks, $m / z$
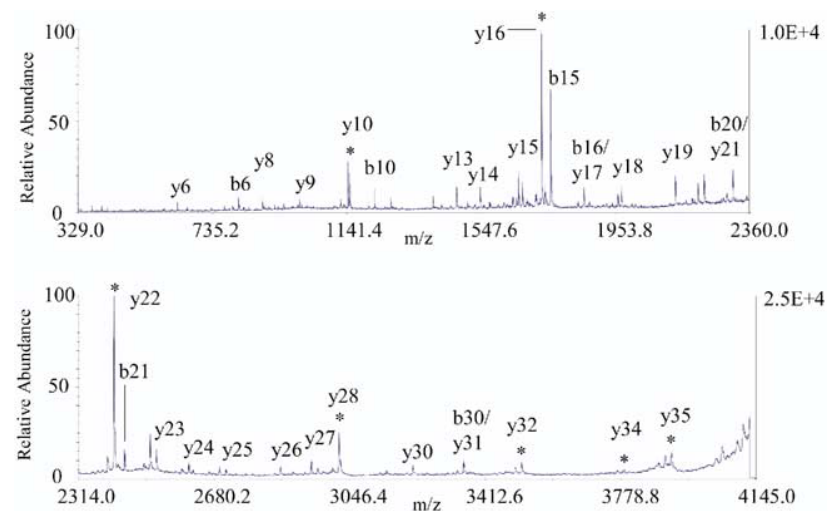

Figure 7. MALDI TOF-TOF spectrum of human glucagon-like peptide $(\mathrm{m} / \mathrm{z} 4169.5$ selected). The $\mathrm{y}$ - and b-ions detected are listed in Table 3. Preferential cleavages at acidic residues and proline residues are indicated by asterisks. 
Table 3. Theoretical and measured masses of MALDI TOF-TOF production ions of human glucagons-like peptide. Over $90 \%$ of $\mathrm{b}$ - and $\mathrm{y}$-ions are observed under optimized condition

\begin{tabular}{|c|c|c|c|c|c|}
\hline T1 & Theoretical & Measured & & Theoretical & Measured \\
\hline y1 & 76.04 & & & & \\
\hline$y 2$ & 232.14 & 232.14 & b2 & 253.09 & 253.07 \\
\hline y3 & 289.16 & 289.14 & b3 & 382.14 & 382.08 \\
\hline y4 & 417.26 & 417.19 & b4 & 529.2 & 529.09 \\
\hline y5 & 516.33 & 516.24 & b5 & 658.25 & 658.08 \\
\hline y6 & 629.41 & 629.26 & b6 & 814.35 & 814.15 \\
\hline y7 & 815.49 & 815.29 & b7 & 951.41 & 951.19 \\
\hline y8 & 886.53 & 886.32 & b8 & 1022.44 & 1022.20 \\
\hline y9 & 999.61 & 999.38 & b9 & 1151.49 & 1151.22 \\
\hline y10 & 1146.68 & 1146.41 & b10 & 1208.51 & 1208.22 \\
\hline y11 & 1275.72 & 1275.42 & b11 & 1309.56 & 1309.22 \\
\hline y12 & 1403.82 & 1403.50 & b12 & 1456.62 & 1456.30 \\
\hline y13 & 1474.85 & 1474.48 & b13 & 1557.67 & 1557.34 \\
\hline y14 & 1545.89 & 1545.54 & b14 & 1644.7 & 1644.39 \\
\hline y15 & 1673.95 & 1673.57 & b15 & 1759.73 & 1759.34 \\
\hline y16 & 1730.97 & 1730.58 & b16 & 1858.8 & 1858.58 \\
\hline y17 & 1860.01 & 1859.58 & b17 & 1945.83 & 1945.41 \\
\hline y18 & 1973.1 & 1972.65 & b18 & 2032.86 & 2032.42 \\
\hline y19 & 2136.16 & 2135.71 & b19 & 2195.93 & 2195.44 \\
\hline y20 & 2223.19 & 2222.72 & b20 & 2309.01 & 2309.72 \\
\hline y21 & 2310.22 & 2310.70 & b21 & 2438.05 & 2437.53 \\
\hline y22 & 2409.29 & 2408.77 & b22 & 2495.08 & 2495.49 \\
\hline y23 & 2524.32 & 2523.79 & b23 & 2623.13 & 2623.54 \\
\hline y24 & 2611.35 & 2610.81 & b24 & 2694.17 & 2693.76 \\
\hline y25 & 2712.4 & 2711.83 & b25 & 2765.21 & 2764.65 \\
\hline y26 & 2859.47 & 2858.87 & b26 & 2893.3 & 2892.72 \\
\hline y27 & 2960.52 & 2959.95 & b27 & 3022.35 & 3021.77 \\
\hline y28 & 3017.54 & 3016.93 & b28 & 3169.41 & 3168.74 \\
\hline y29 & 3146.58 & 3145.91 & b29 & 3282.5 & 3282.95 \\
\hline y30 & 3217.62 & 3217.00 & b30 & 3353.54 & 3353.87 \\
\hline y31 & 3354.68 & 3354.02 & b31 & 3539.61 & \\
\hline y32 & 3510.78 & 3510.08 & b32 & 3652.7 & \\
\hline y33 & 3639.82 & & b33 & 3751.77 & \\
\hline y34 & 3786.89 & 3787.96 & b34 & 3879.86 & \\
\hline y35 & 3915.93 & 3915.86 & b35 & 3936.88 & 3937.89 \\
\hline y36 & 4030.96 & & b36 & 4092.98 & 4092.15 \\
\hline
\end{tabular}

1086.43 and 1272.47 , corresponding to the $\mathrm{y} 9$ and $\mathrm{y} 11$ ions of insulin B-chain, respectively, dominate this region. Preferential cleavage occurring C-terminal of glutamic acid (position 9) yields the intense y9 peak; however, the intense y11 peak, results from cleavage of a Cys-Gly bond. There is no previous suggestion of the lability of Cys-Gly bond. Other products ions apart from the two $y$-series product ions, both b-ions and y-ions, of insulin B-chain, were also detected. Although the intensities of these product ions are not strong, their observation provides important sequence information.

The quintet in Figure 8c, formed by asymmetric cleavage of both disulfide bonds connecting the two chains with charge located on the B-chain, were observed using both standard and modified settings. The counterpart product ion with the charge located on the A-Chain (Figure 8b) was only observed using modified settings. In contrast to the quintet, several triplets with mass difference of $32 / 33 \mathrm{Da}$ were observed in this region, indicating the sequential loss of $\mathrm{R}, \mathrm{RS}$, or RSS groups.

\section{Conclusions}

Optimization of a MALDI TOF-TOF mass spectrometer was performed on Applied Biosystems 4700 proteomics analyzer instrument for direct analysis of proteins up to $12,000 \mathrm{Da}$. Both the focus of the precursor ion beam before entering the collision cell (controlled by the voltages applied to the grid and einzel lens) and the delay time of ion extraction in ion source 1 are the two significant factors that affected instrument sensitivity. Eight matrices were evaluated and CHCA was found to provide the most intense signal in TOF-TOF experiments. Under optimal conditions, more than $90 \%$ of band $y$-fragment ions were observed for peptides up to $4200 \mathrm{Da}$. Asymmetric and symmetric cleavages of insulin disulfide bond as well as fragmentation of chain $b$ were also observed with enhanced intensity. These results indicate that the MALDI TOF-TOF experiment can provide structural information for proteins as large as $12 \mathrm{kDa}$ with sufficient sensitivity for protein identification and analysis of posttranslational modifications. 

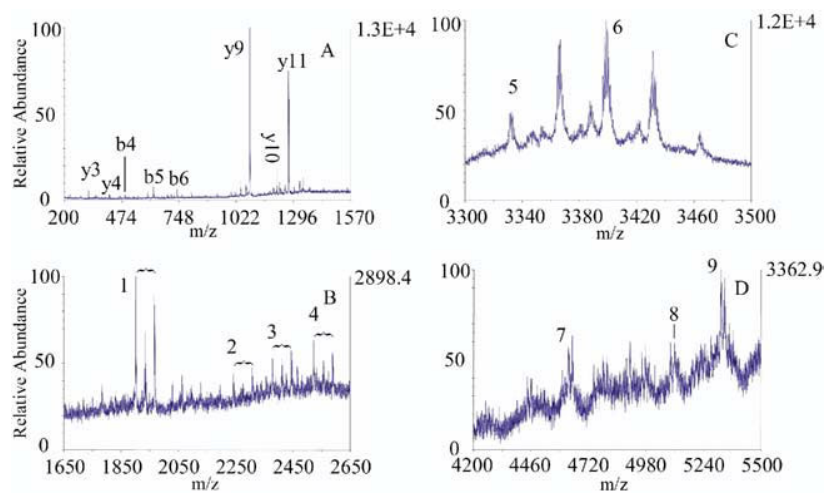

Figure 8. Four segments of the tandem mass spectrum of insulin revealing different structural information. (a) Low mass segment representing the product ions generated from the cleavage of insulin B-chain. (b) Cleavage of disulfide bonds linking chain A and chain $B$ (separated by mass difference $32 / 33 \mathrm{Da}$, shown by brackets) and the cleavage of chain A and chain B, respectively. (c) Product ions resulting from the asymmetric and symmetric cleavage of both S-S bonds connecting the A-chain and B-chain. (d) High mass segment of MS/MS spectrum of insulin presenting the cleavages of residues from $\mathrm{N}$-terminus, leaving at least one disulfide bond between A-chain and B-chain intact. Peak labeling: 1: [y17 of B-chain $\left.(-\mathrm{SH})-\mathrm{H}_{2} \mathrm{~S}+\mathrm{H}\right]^{+}, 2$ : [A-chain $(-\mathrm{SH})-\mathrm{SH}-\mathrm{SH}+\mathrm{H}^{+}$, 3: $[\text { A-chain-Cys }+\mathrm{H}]^{+}, 4$ : [A-chain-Cys-Leu $\left.(-\mathrm{SH}-\mathrm{SH})+\mathrm{H}\right]^{+}, 5$ : [B-chain(-SH-SH)- $\left.2 \mathrm{H}_{2} \mathrm{~S}+\mathrm{H}\right]^{+}, 6$ : [B-chain $\left.(-\mathrm{SH}-\mathrm{S})\right]^{+}, 7$ : [B-chain-Achain-GIVEQCCASVC $+\mathrm{H}]^{+}$, 8: [B-chain-A-chain-GIVEQC $\left.+\mathrm{H}\right]^{+}$, 9: $[\mathrm{B}-\text { chain-A-chain-GIVE }+\mathrm{H}]^{+}$.

\section{Acknowledgments}

This work is financially supported by the National Institute of Health (NIH NO1-HV-28281).

\section{References}

1. Karas, M.; Hillenkamp, F. Laser desorption ionization of proteins with molecular masses exceeding 10,000 daltons. Anal. Chem. 1988, 60, 2299-2301.

2. Tanaka, K.; Waki, H.; Ido, Y.; Akita, S.; Yoshida, Y.; Yoshida, T. Protein and plolymer analyses up to $m / z 100,000$ by laser ionization time-of-flight mass spectrometry. Rapid Commun. Mass Spectrom. 1988, 2, 151-153.

3. Hillenkamp, F.; Karas, M.; Beavis, R. C.; Chait, B. T. Matrixassisted laser desorption/ionization of biopolymers. Anal. Chem. 1991, 63, 1193A-1203A.

4. Fenn, J.; Mann, M.; Meng, C. K.; Wong, S. F.; Whitehouse, C. M. Electrospray ionization for mass spectrometry of large biomelecues. Science 1989, 246, 64-71.

5. Ferguson, P. L.; Smith, R. D. Proteome analysis by mass spectrometry. Annu. Rev. Biophys. Biomol. Struct. 2003, 32, 399-424.

6. Ong, S. E.; Pandey, A. An evaluation of the use of twodimensional gel electrophoresis in proteomics. Biomol. Eng. 2002, 18, 195-205.

7. Medzihradszky, K. F.; Campbell, J. M.; Baldwin, M. A.; Falick, A. M.; Juhasz, P.; Vestal, M. L.; Burlingame, A. L. The characteristics of peptide collision-induced dissociation using a high-performance MALDI-TOF/TOF tandem mass spectrometer. Anal. Chem. 2000, 72, 552-558.

8. Zubarev, R. A.; Kelleher, N. L.; McLafferty, F. W. Electron capture dissociation of multiply charged protein cations. A nonergodic process. J. Am. Chem. Soc. 1998, 120, 3265-3266.
9. Reid, G. E.; McLuckey, S. A. "Top down" protein characterization via tandem mass spectrometry. J. Mass Spectrom. 2002, $37,663-675$.

10. Ge, Y.; Lawhorn, B. G.; El Naggar, M.; Strauss, E.; Park, J. H.; Begley, T. P.; McLafferty, F. W. Top down characterization of larger proteins $(45 \mathrm{kDa})$ by electron capture dissociation mass spectrometry. J. Am. Chem. Soc. 2002, 124, 672-678.

11. Horn, D. M.; Zubarev, R. A.; McLafferty, F. W. Automated de novo sequencing of proteins by tandem high-resolution mass spectrometry Proc. Natl. Acad. Sci. U.S.A. 2000, 97, 1031310317.

12. Horn, D. M.; Ge, Y.; McLafferty, F. W. Activated ion electron capture dissociation for mass spectral sequencing of larger (42 kDa) proteins. Anal. Chem. 2000, 72, 4778-4784.

13. Gross, M. L.; Tomer, K. B.; Cerny, R. L.; Giblin, D. E. FAB and tandem MS for structure determination of biomolecules: Success to $\mathrm{m} / \mathrm{z} 2000$ and prospects for higher mass. In Mass Spectrometry in the Analysis of Large Molecules; McNeal, C. J., Ed.; John Wiley and Sons: Chichester, 1986; pp 171-190.

14. Neumann, G. M; Derrick, P. J. Energy transfer in the collision induced decomposition of peptide ions formed by field desorption. Org. Mass Spectrom. 1984, 19, 165-170.

15. Feng, R.; Konishi, Y. Collisionally-activated dissociation of multiply charged $150 \mathrm{kDa}$ antibody ions. Anal. Chem. 1993, 65, 650-652.

16. Brown, R. S.; Lennon, J. J. Sequence-specific fragmentation of matrix-assisted laser-desorbed protein peptide ions. Anal. Chem. 1995, 67, 3990-3999.

17. Katta, V.; Chow, D. T.; Rohde, M. F. Applications of in-source fragmentation of protein ions for direct sequence analysis by delayed extraction MALDI-TOF mass spectrometry. Anal. Chem. 1998, 70, 4410-4416.

18. Lennon, J. J.; Walsh, K. A. Direct sequence analysis of proteins by in-source fragmentation during delayed ion extraction. Prot. Sci. 1997, 6, 2446-2453.

19. Takayama, M.; Tsugita, A. Sequence information of peptides and proteins with in-source decay in matrix assisted laser desorption/ionization-time of flight-mass spectrometry. Electrophoresis 2000, 21, 1670-1677.

20. Takayama, M. In-source decay characteristics of peptides in matrix-assisted laser desorption/ionization time-of-flight mass spectrometry. J. Am. Soc. Mass Spectrom. 2001, 12, 420427.

21. Takayama, M.; Tsugita, A. Does in-source decay occur independent of the ionization process in matrix-assisted laser desorption? Int. J. Mass Spectrom. 1998, 181, L1-L6.

22. Yu, W.; Vath, J. E.; Huberty, M. C.; Martin, S. A. Identification of the facile gas-phase cleavage of the Asp-Pro and Asp$\mathrm{Xxx}$ peptide bonds in matrix-assisted laser desorption timeof-flight mass spectrometry. Anal. Chem. 1993, 65, 3015-3023.

23. Suckau, D; Resemann, A.; Schuerenberg, M.; Hufnagel, P.; Franzen, J.; Holle, A. A novel MALDI LIFT-TOF/TOF mass spectrometer for proteomics. Anal. Bioanal. Chem. 2003, 376, 952-965.

24. Suckau, D.; Resemann, A. T-3-sequencing: Targeted characterization of the $\mathrm{N}$ - and $\mathrm{C}$-termini of undigested proteins by mass spectrometry. Anal. Chem. 2003, 75, 5817-5824.

25. Lin, M.; Campbell, J. M.; Mueller, D. R.; Wirth, U. Intact protein analysis by matrix-assisted laser desorption/ionization tandem time-of-flight mass spectrometry. Rapid Commun. Mass Spectrom. 2003, 17, 1809-1814.

26. Qin, J.; Chait, B. T. Collision-induced dissociation of singly charged peptide ions in a matrix-assisted laser desorption ionization ion trap mass spectrometer. Int. J. Mass Spectrom. 1999, 190/191, 313-320.

27. Yergey, A. L.; Coorssen, J. R.; Backlund, P. S.; Blank, P. S.; Humphrey, G. A.; Zimmerberg, J.; Campbell, J. M.; Vestal, 
M. L. De novo sequencing of peptides using MALDI/TOF-TOF. J. Am. Soc. Mass Spectrom. 2002, 13, 784-791.

28. Brown, R. S.; Lennon, J. J. Mass resolution improvement by incorporation of pulsed ion extraction in a matrix-assisted laser-desorption ionization linear time-of-flight mass-spectrometer. Anal. Chem. 1995, 67, 1998-2003.

29. Wang, B. H.; Dreisewerd, K.; Bahr, U.; Karas, M.; Hillenkamp, F. Gas-phase cationization and protonation of neutrals generated by matrix-assisted saser desorption. J. Am. Soc. Mass Spectrom. 1993, 4, 393-398.

30. Karas, M.; Bahr, U.; Strupat, K.; Hillenkamp, F.; Tsarbopoulos, A.; Pramanik, B. N. Matrix dependence of metastable fragmentation of glycoproteins in MALDI TOF mass spectrometry. Anal. Chem. 1995, 67, 675-679.

31. Beavis, R. C.; Chaudhary, T.; Chait, B. T. Org. Mass Spectrom. 1992, 27, 156.

32. Beavis, R. C.; Chait, B. T. Rapid Commun. Mass Spectrom. 1989, 3, 233-237.

33. Juhasz, P.; Costello, C. E.; Biemann, K. Matrix-assisted laser desorption ionization mass spectrometry with 2-(4-hydroxyphenylazo)benzoic acid matrix. J. Am. Soc. Mass Spectrom. 1993, 4, 399-409.

34. Xu, N.; Huang, Z.; Watson, J.; Gage, D. MercaptobenzothiazolesA new class of matrices for laser desorption ionization mass spectrometry. J. Am. Soc. Mass Spectrom. 1997, 8, 116-124.

35. Danis, P. O.; Karr, D. E.; Simonsick, W. J.; Wu, D. T. Matrixassisted laser desorption ionization time-of-flight mass spectrom- etry characterization of poly(butyl methacrylate)synthesized by group-transfer polymerization. Macromol. 1995, 28, 1229-1232.

36. Brown, R. S.; Durrant, E. E. Metastable ion decay in IRMALDI: Charge state and desorption wavelength effects. Proceedings of the 51st ASMS Annual Conference on Mass Spectrometry and Allied Topics; Montreal, Canada, June 2003.

37. Liu, Z. Y.; Russell, D. H.; Sumner, L.W. Ion-to-Neutral Ratios: A unique measure of internal energy content of MALDI ions. Proceedings of the 50th ASMS Annual Conference on Mass Spectrometry and Allied Topics; Orlando, FL, June 2002.

38. Wysocki, V. H.; Tsaprailis, G.; Smith, L. L.; Breci, L. A. Mobile and localized protons: A framework for understanding peptide dissociation. J. Mass Spectrom. 2000, 35, 1399-1406.

39. Jones, M. D.; Patterson, S. D.; Lu, H. S. Determination of disulfide bonds in highly bridged disulfide-linked peptides by matrix-assisted laser desorption/ionization mass spectrometry with postsource decay. Anal. Chem. 1998, 70, 136-143.

40. Brown, R. S.; Carr, B. L.; Lennon, J. J. Factors that influence the observed fast fragmentation of peptides in matrix-assisted laser desorption. J. Am. Soc. Mass Spectrom. 1996, 7, 225-232.

41. Frankevich, V.; Zhang, J.; Dashtiev, M.; Zenobi, R. Production and fragmentation of multiply charged ions in "electron-free" matrix-assisted laser desorption/ionization. Rapid Commun. Mass Spectrom. 2003, 17, 2343-2348.

42. Loo, J. A.; Edmonds, C. G.; Smith, R. D. Tandem mass spectrometry of very large molecules. 2. Dissociation of multiply charged proline-containing proteins from electrospray ionization. Anal. Chem. 1993, 55, 425-438. 